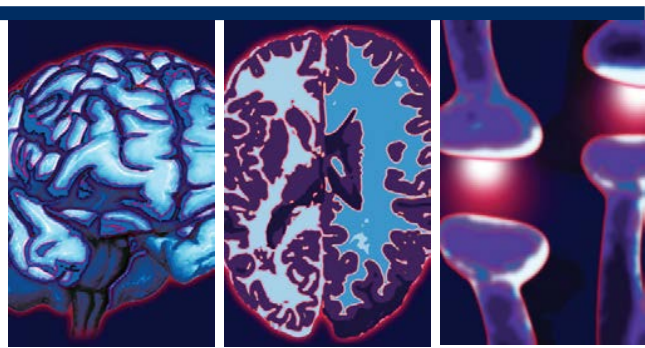

\title{
Relationship between Schizophrenia and Low-Income Based on Age and Sex: Results from a Nation-wide Population-Based Longitudinal Study
}

Chun-Te Lee ${ }^{1,2}$, Chiu-Yueh Hsiao ${ }^{3}$, Jia-Fu Lee ${ }^{4,5}$, Yi-Chyan Chen ${ }^{4,5}$, Oswald Ndi Nfor ${ }^{6}$, Jing-Yang Huang ${ }^{6}$, Lee Wang ${ }^{6}$, Chien-Chang $\mathrm{Ho}^{7}$, Yung-Po Liaw,

\begin{abstract}
Background: The aim of this study was to examine the relationship between low-income and schizophrenia among the Taiwanese population.

Methods and Findings: We recruited 1,773,693 participants (15,098 low-income and 1,758,595 non-low-income individuals) from the National Health Insurance Research Database (NHIRD). Low-income individuals were identified in 2001-2003 and followed up from 2004 to 2010 to ascertain a positive diagnosis of Schizophrenia. Cox proportional hazard regression analysis was used to determine the hazard ratios (HRs) with their $95 \%$ confidence interval (Cl). The attributable risk percent (AR\%) was also determined. The prevalence of schizophrenia was $0.26 \%$ in non-low-income and $1.23 \%$ in low-income individuals. In the low-income group, the incidence rates were $0.71(0.45-1.11), 3.46$ (2.61-4.57), 3.22 (2.22-4.66), and $1.67(0.97-2.87)$ per 10,000 person-months in men, and 0.31 (0.16-0.59), 1.85 (1.40-2.46), 1.48 (0.80-2.75), and 1.86 (0.97-3.57) per 10,000 person-months in women aged 0-17, $18-44,45-64$ and $\geq 65$ years, respectively. Higher incidence rates were evident in the 18-64 age category of low-income individuals. The adjusted HRs were 4.06 (2.52-6.53), 6.42 (4.82-8.58), 13.03 (8.80-19.30), and 7.48 (4.22-13.28) in low-income men, and 1.87 (0.96-3.66), 4.66 (3.48-6.23), 4.02 (2.15-7.53), and 5.47 (2.79-10.72) in low-income women aged 0-17, 18-44, 45-64, and $\geq 65$ years, respectively. The adjusted AR\% of schizophrenia were $75.4 \%, 84.4 \%, 92.3 \%$, and $86.6 \%$ in low-income males, and $46.6 \%, 78.5 \%, 75.1 \%$, and $81.7 \%$ in low-income females of above age categories.
\end{abstract}

Conclusions: Schizophrenia was more common in low-income individuals compared to their non-low-income counterparts. In the low income group, schizophrenia was more common in men than in women under 65.

\section{Keywords}

Schizophrenia; Low income; Household income; Longitudinal study

\footnotetext{
'Department of Psychiatry, Chung Shan Medical University Hospital, Taichung City, Taiwan

${ }^{2}$ School of Medicine, Chung Shan Medical University, Taichung City, Taiwan

${ }^{3}$ Department of Nursing, College of Medical and Health Science, Asia University, Taichung City, Taiwan

${ }^{4}$ Department of Psychiatry, Taipei Tzu Chi Hospital, Buddhist Tzu Chi Medical Foundation, New Taipei City, Taiwan

${ }^{5}$ Department of Psychiatry, School of Medicine, Tzu Chi University, Hualien, Taiwan

${ }^{6}$ Department of Public Health and Institute of Public Health, Chung Shan Medical University, Taichung City, Taiwan

${ }^{7}$ Department of Physical Education, Fu Jen Catholic University, New Taipei City, Taiwan

${ }^{8}$ Department of Family and Community Medicine, Chung Shan Medical University Hospital, Taichung City, Taiwan

${ }^{\dagger}$ Author for correspondence: Yung-Po Liaw, Department of Public Health and Institute of Public Health, Chung Shan Medical University; Department of Family and Community Medicine, Chung Shan Medical University Hospital, No. 110, Sec. 1 Jianguo N. Rd., Taichung City 40201, Taiwan, Tel: +886-4-24730022 ext.11838; Fax: +886-4-23248179; email: Liawyp@csmu.edu.tw
} 


\begin{abstract}
Abbreviations
NHIRD: National Health Insurance Research Database, ICD-9-CM: International Classification of Diseases Revision 9 Clinical Modification, HR: Hazard Ratio, CI: Confidence Interval, LHID: Longitudinal Health Insurance Database
\end{abstract}

\section{Introduction}

Socioeconomic status is strongly associated with schizophrenia. Some of the socioeconomic risk factors associated with schizophrenia include income inequality [1], socio-economic deprivation [2-4], urbanicity [5], migration $[6,7]$, and lower parental socio-economic status [8]. These studies have also associated poverty and economic distress with schizophrenia. Among some of the studies that have investigated the association between low-income and schizophrenia, Sareen and colleagues found that lower level of household income significantly increased the likelihood of schizophrenia [9]. Another study has also found an association between schizophrenia and parental lower income [10]. However, a previous study investigating 405 cases (aged 16 to 35 years) with first episodes of schizophrenia found no association between lowincome and the incidence of schizophrenia [11]. In the aforementioned studies, relationships were not investigated based on low-income, age, and gender. Moreover, results from those studies were inconsistent probably due to differences in methodology and urbanization levels.

To date, large-scale cohort studies investigating the relationship between low-income and schizophrenia have not been conducted among different gender and age groups. Therefore, in this population-based 10-year follow-up study, we investigated the relationship between lowincome and schizophrenia based on age and sex. This study had three major objectives: (1) To investigate whether low-income is a risk factor for developing schizophrenia. (2) To investigate the incidence rates of schizophrenia among lowincome individuals based on age and sex. (3) To compare the incidence rates of schizophrenia between low-income and non-low-income individuals in all age and sex groups.

\section{Methods}

Persons who reside in Taiwan for over 6 months are required to enroll in the National Health Insurance (NHI) program. The NHI Bureau transfers all health insurance data to the National Health Insurance Institute (NHRI). The primary data source of this study is the National health Insurance Research Database (NHIRD) which contains detailed healthcare data of approximately 99\% of the general population. Within the NHIRD are the 2005 and 2010 Longitudinal Health Insurance Datasets (LHID) which contain claim data of approximately 2 million randomly sampled individuals. The LHID contain integrated medical records of the sampled individuals from 2001-2010. Lowincome was defined as having family income less than 20,000 NTD (New Taiwan Dollar) per month. We identified low-income individuals that were free of schizophrenia during the period 2001-2003. The same individuals (that is, low-income individuals that did not have schizophrenia previously) were reviewed from 2004-2010 to ascertain schizophrenia positive diagnosis, and the relationship to gender and socioeconomic status.

The clinical diagnosis of schizophrenia was based on the International Classification of Diseases, Revision 9, Clinical Modification (ICD-9-CM) code 296.XX. Exclusions included the following: (1) Individuals who were diagnosed with schizophrenia from 2001 to 2003 ( $\mathrm{n}=8,744$ ). (2) People whose income fluctuated or changed (that is, from non-low-income to low-income) during the period 2004 to 2010 ( $\mathrm{n}=20,689)$. (3) Individuals whose demographic data were incomplete $(n=74)$. The final participants included 1,773,693 individuals $(1,758,595$ from non-low-income and 15,098 from lowincome households). In general, 4,672 people were identified with schizophrenia from 2004 to 2010. The Institutional Review Board of Chung Shan Medical University Hospital approved this study.

\section{- Statistical analyses}

Chi-square tests were used to analyze nominal variables and to compare the proportion of low-income and non-low-income individuals. Cox proportional hazards regression model was used to determine the hazard ratios (HRs) of schizophrenia. Adjustments were made for geographic location and urbanization level. The attributable risk percent (AR\%) of schizophrenia was also determined. We used $p<0.05$ and $95 \%$ confidence interval (CI) to define statistical significance. All analyses were performed using the SAS 9.3 statistical software (SAS Institute, Cary, NC). 
Relationship between Schizophrenia and Low-Income Based on Age and Sex: Results from a Nation-wide Population-Based Longitudinal Study

\section{Results}

The demographic characteristics of the study population are shown in Table 1 . Overall, 15,098 low-income individuals (6,999 men and 8,099 women) and 1,758,595 non-lowincome individuals $(863,966$ men and 894,629 women) were recruited from 2001 to 2003 . The percentage of men was smaller in the low-income than in the non-low-income group $(46.36 \%$ vs $49.13 \%)$. On the contrary, the percentage of women was smaller in the non-low-income than in the low-income group $(50.87 \%$ vs $53.64 \%$ vs). There were significant differences in the number of low-income and non-low-income individuals in different age groups. The 18-44 years age category registered the highest number of non-low-income participants compared to other age groups. On the other hand, the 0-17 years age category had the highest number of low-income individuals (44.95\%) compared to other age groups. There were significant differences between low-income and non-lowincome in relation to geographical location and urbanization level. However, significant differences were not found between lowincome and non-low income participants after stratification by Charlson comorbidity index. From 2004 to 2010, Schizophrenia was found to be more common in low-income compared to non-low-income individuals ( $1.23 \%$ vs $0.26 \%)$.

Table 2 shows the incidence rates of schizophrenia among the study participants according to age group and sex. The rates were higher in lowincome men under the age of 65 compared to the women in the same age group. The values were $0.71(0.45-1.11), 3.46$ (2.61-4.57), 3.22 (2.22-4.66), and $1.67(0.97-2.87)$ per 10,000 person-months in low-income men, and 0.31 (0.16-0.59), 1.85 (1.40-2.46), 1.48 (0.80-2.75), and $1.86(0.97-3.57)$ per 10,000 person-months in low-income women aged 0-17, 18-44, 45-64 and $\geq 65$ years, respectively. Broadly speaking, the incidence rates of schizophrenia were higher in the low-income compared to non-low-income individuals in all age and sex groups. The values were 0.71 vs $0.16,3.46$ vs $0.44,3.22$ vs 0.23 , and 1.67 vs 0.22 per 10,000 person-months in men, and 0.31 vs $0.16,1.85$ vs $0.36,1.48$ vs 0.34 vs and 1.86 vs 0.33 per 10,000 person-months in women aged $0-17,18-44,45-64$ and $\geq 65$ years, respectively. Among low-income individuals, the male to female incidence ratio was highest in the 0-17 age group (2.29). However, the highest ratio among non-low-income individuals was found in the 18-44 age group (1.22). The incidence rate

\begin{tabular}{|c|c|c|c|c|c|}
\hline $\begin{array}{l}\text { Variables } \\
\text { Sex }\end{array}$ & \multicolumn{2}{|c|}{$\begin{array}{l}\text { Non-low-income } \\
\text { Individuals } \\
(\mathrm{n}=1,758,595)\end{array}$} & \multicolumn{2}{|c|}{$\begin{array}{l}\text { Low-income } \\
\text { Individuals } \\
\text { ( } n=15,098)\end{array}$} & $\boldsymbol{p}$ \\
\hline Men & 863,966 & (49.13\%) & 6,999 & $(46.36 \%)$ & \\
\hline Women & 894,629 & $(50.87 \%)$ & 8,099 & (53.64\%) & \\
\hline Age in 2003 (years) & & & & & $<0.0001$ \\
\hline $0-17$ & 452,091 & (24.17\%) & 6,786 & (44.95\%) & \\
\hline $18-44$ & 800,591 & (45.52\%) & 4,885 & $(32.36 \%)$ & \\
\hline $45-64$ & 386,880 & $(22.00 \%)$ & 1,886 & $(12.49 \%)$ & \\
\hline$\geq 65$ & 146,033 & (8.30\%) & 1,541 & (10.21\%) & \\
\hline Geographical location & & & & & $<0.0001$ \\
\hline Taipei area & 643,301 & $(36.58 \%)$ & 5,145 & (34.08\%) & \\
\hline North area & 243,478 & (13.85\%) & 1,333 & (8.83\%) & \\
\hline Central area & 325,851 & (18.53\%) & 2,040 & (13.51\%) & \\
\hline South area-1 & 247,036 & $(14.05 \%)$ & 1,924 & $(12.74 \%)$ & \\
\hline South area-2 & 261,099 & $(14.85 \%)$ & 3,076 & (20.37\%) & \\
\hline East area & 37,830 & $(2.15 \%)$ & 1,580 & (10.46\%) & \\
\hline Urbanization level & & & & & $<0.0001$ \\
\hline Urban & $1,087,387$ & (61.83\%) & 7,112 & (47.11\%) & \\
\hline Normal & 521,126 & $(29.63 \%)$ & 4,643 & (30.75\%) & \\
\hline Rural & 150,082 & $(8.53 \%)$ & 3,343 & (22.14\%) & \\
\hline Charlson comorbidity index & & & & & 0.0234 \\
\hline $0-1$ & $1,440,159$ & (81.89\%) & 12,234 & (81.03\%) & \\
\hline $2-7$ & 305,988 & (17.40\%) & 2,753 & (18.23\%) & \\
\hline$\geq 8$ & 12,448 & $(0.71 \%)$ & 111 & $(0.74 \%)$ & \\
\hline $\begin{array}{l}\text { Diagnosed with schizophrenia } \\
(2004-2010)\end{array}$ & 4,487 & $(0.26 \%)$ & 185 & $(1.23 \%)$ & $<0.0001$ \\
\hline
\end{tabular}

ratios (IRRs) were 4.43, 7.86, 14.00, and 7.59 in men, and $1.94,5.14,4.35$, and 5.64 in women aged $0-17,18-44,45-64, \geq 65$ years, respectively (Figure 1).

Figure 2 shows the HRs (risk of schizophrenia in low-income compared with non-lowincome individuals), as well as the AR\% (the percent of the incidence of schizophrenia in the exposed that is due to low-income) by gender and various age groups. After adjusting for geographic location and urbanization level in the Cox proportional hazard regression model, the HRs with their 95\% CI were 4.06 (2.526.53), 6.42 (4.82-8.58), 13.03 (8.80-19.30), and $7.48(4.22-13.28)$ in low-income men, and $1.87(0.96-3.66), 4.66(3.48-6.23), 4.02$ $(2.15-7.53)$, and $5.47(2.79-10.72)$ in lowincome women aged $0-17,18-44,45-64$, and $\geq 65$ years, respectively. The adjusted AR\% of schizophrenia were $75.4 \%, 84.4 \%, 92.3 \%$, and $86.6 \%$ in low-income men, and $46.6 \%$, $78.5 \%, 75.1 \%$, and $81.7 \%$ in low-income women of the above age groups. By and large, the HRs and ARs were higher in men than women of all age groups. 
Research Yung-Po Liaw

\begin{tabular}{|c|c|c|c|c|c|c|c|c|}
\hline & \multicolumn{8}{|l|}{ Age category } \\
\hline & \multicolumn{2}{|l|}{$0-17$} & \multicolumn{2}{|l|}{$18-44$} & \multicolumn{2}{|l|}{$45-64$} & \multicolumn{2}{|l|}{$\geq 65$} \\
\hline & $\begin{array}{l}\text { Non-low- } \\
\text { income }\end{array}$ & Low-income & $\begin{array}{l}\text { Non-low- } \\
\text { income }\end{array}$ & Low-income & $\begin{array}{l}\text { Non-low- } \\
\text { income }\end{array}$ & Low-income & $\begin{array}{l}\text { Non-low- } \\
\text { income }\end{array}$ & Low-income \\
\hline \multicolumn{9}{|l|}{ Men } \\
\hline $\begin{array}{l}\text { Person-months } \\
\text { at risk }\end{array}$ & $18,115,134$ & 268,670 & $31,814,923$ & 141,773 & $15,704,756$ & 86,986 & $5,951,459$ & 77,963 \\
\hline Cases & 296 & 19 & 1,415 & 49 & 355 & 28 & 131 & 13 \\
\hline Incidence rate ${ }^{*}(\mathrm{Cl})$ & $0.16(0.15-0.18)$ & $0.71(0.45-1.11)$ & $0.44(0.42-0.47)$ & $3.46(2.61-4.57)$ & $0.23(0.20-0.25)$ & $3.22(2.22-4.66)$ & $0.22(0.19-0.26)$ & $1.67(0.97-2.87)$ \\
\hline \multicolumn{9}{|l|}{ Women } \\
\hline $\begin{array}{l}\text { Person-months } \\
\text { at risk }\end{array}$ & $17,144,434$ & 293,417 & $34,505,623$ & 258,974 & $16,355,307$ & 67,549 & $6,135,036$ & 48,476 \\
\hline Cases & 273 & 9 & 1,248 & 48 & 564 & 10 & 205 & 9 \\
\hline Incidence rate ${ }^{*}(\mathrm{Cl})$ & $0.16(0.14-0.18)$ & $0.31(0.16-0.59)$ & $0.36(0.34-0.38)$ & $1.85(1.40-2.46)$ & $0.34(0.32-0.37)$ & $1.48(0.80-2.75)$ & $0.33(0.29-0.38)$ & $1.86(0.97-3.57)$ \\
\hline \multicolumn{9}{|c|}{$\mathrm{Cl}=95 \%$ confidence interval, ${ }^{*}$ Per $10^{4}$ person-months. } \\
\hline
\end{tabular}

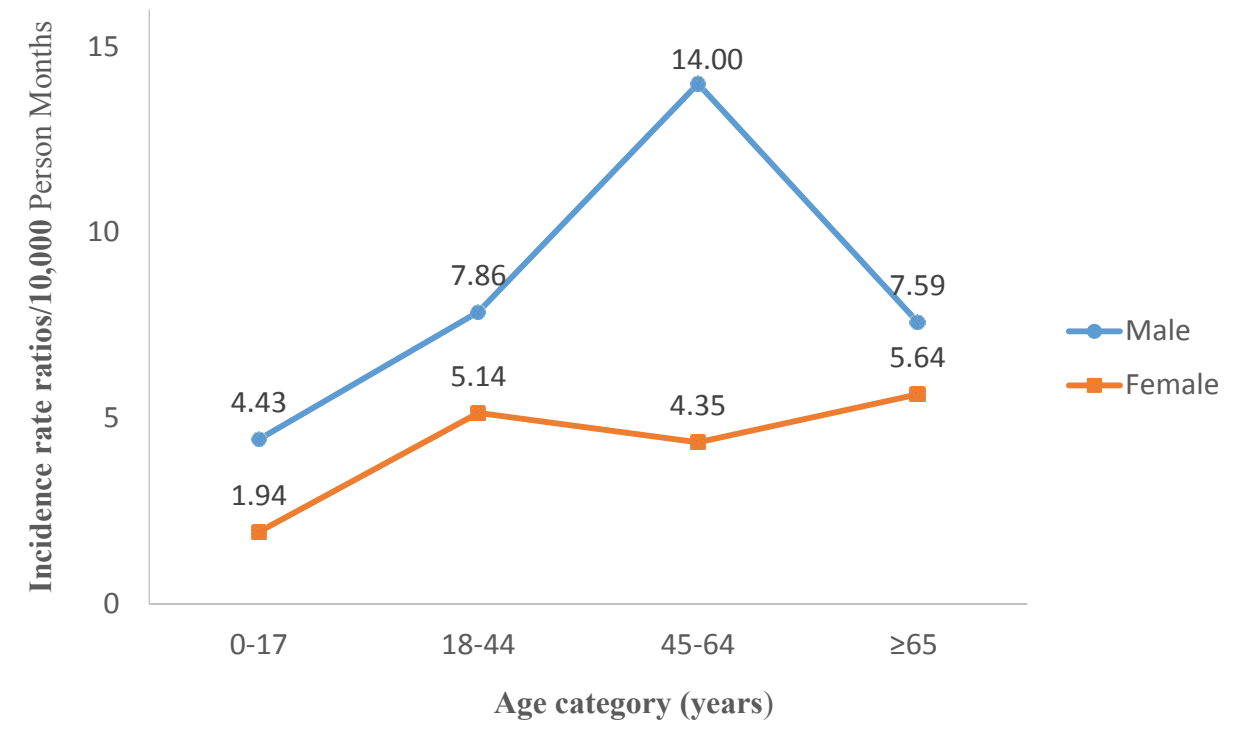

Figure 1: Incidence rate ratio of schizophrenia according to age category and gender.

\section{Discussion}

In this 10-year longitudinal follow-up study, we found that, 1) low-income was a risk factor for schizophrenia in both men and women. (2) The incidence rates of schizophrenia were higher in low-income compared to non-lowincome individuals in all age and sex groups. (3) In the low-income group, schizophrenia was more common in men than women under the age of 65 . To our knowledge, this is the first study to investigate the relationship between schizophrenia and low-income based on gender and age groups. The incidence rates $/ 10,000$ person-months of schizophrenia ranged from $0.16-0.44$ and 0.31-3.46 in non-lowincome and low-income groups, respectively.
Similar results have been found in previous publications [12,13]. Among the low-income group, the incidence ratios of schizophrenia (men to women) were approximately 2.29 , $1.87,2.18$, in the $0-17,18-44,45-64$ age groups, respectively. It is worth stating that the incidence rates were significantly higher in men compared to women, with a peak at age 18-64 years. This shows that this age category may serve as a target group in the prevention of schizophrenia. Nonetheless, another study has reported a peak onset occurring typically between the ages of 15-25 [14]. The higher incidence observed in men is an indication that the diseases is expressed differently between sexes [15]. 


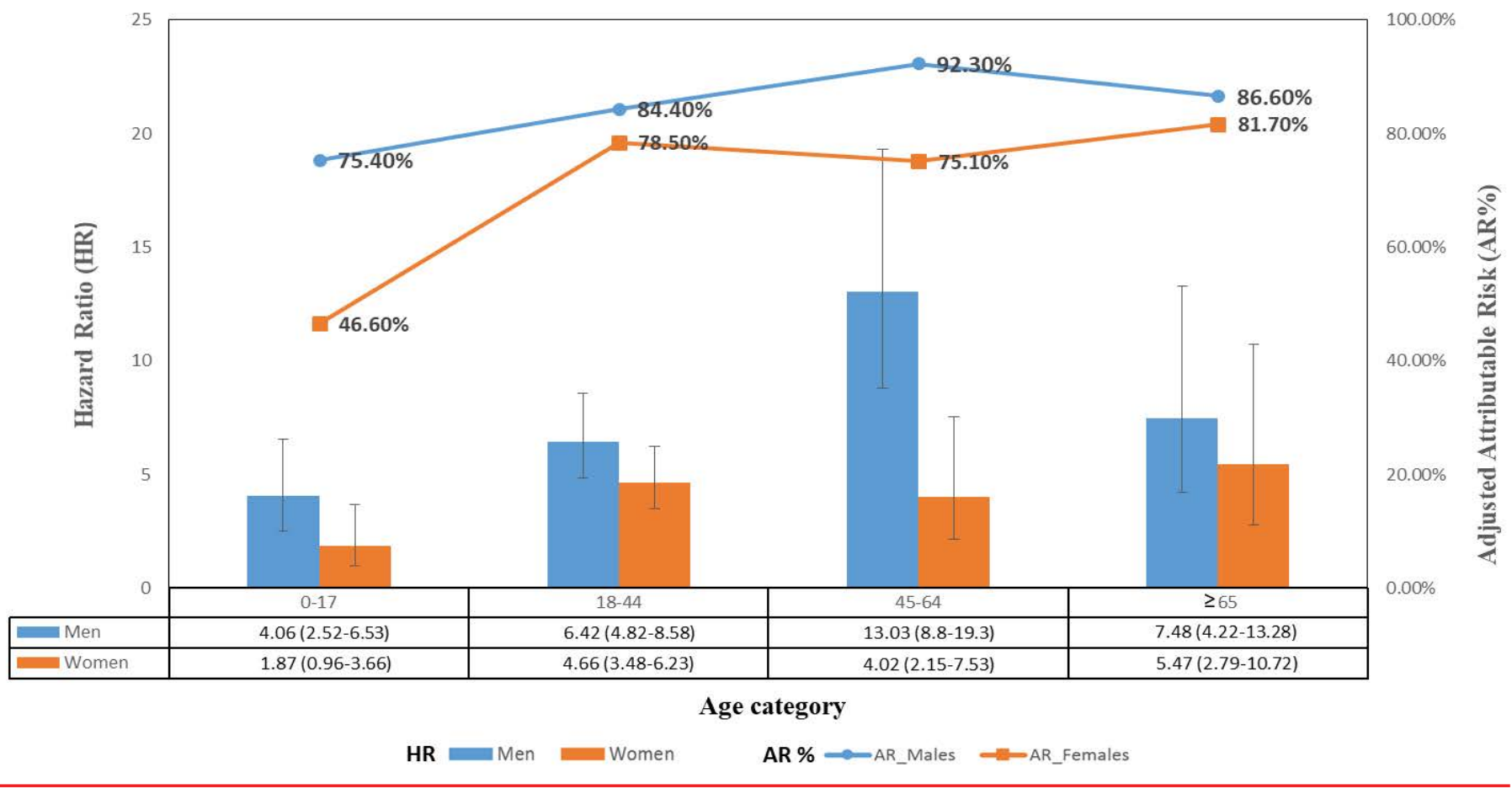

Figure 2: Hazard ratios and adjusted attributable risk percent of schizophrenia among low-income individuals.

A number of studies have found strong associations between low-income and mental disorders [16-19]. Our observations align with previous findings although age and sex were not included in their analyses $[9,10]$ Inconsistent results have also been reported [11]. In a cross-sectional study of the first episode of schizophrenia among persons aged 16 to 35 years, low-income did not predict the incidence of schizophrenia [2]. The inconsistent results reported in previous publications cited above may partly be linked to the role of economic stressor, malnutrition, obstetrical complications, violence, family dysfunction, social deprivation, social adversity, and a decrease capacity to obtain good health care $[9,10,20,21]$.

Two principal causal pathways (social causation and social drift) have been suggested for the development of schizophrenia [22]. A previous study found that the first admission with schizophrenia was concentrated among lower socio-economic areas of Chicago [2]. This has been consistently replicated by other studies $[22,23]$. However, another study found no difference in the incidence of schizophrenia based on social class [24] Other studies have associated higher social class at birth with increased risk of schizophrenia $[25,26]$. Taken together, there are some discrepancies between the social class and factors related to schizophrenia. This may be due to differences in the samples, methodology, and diverse meaning of social class in different generations. Generally speaking, genetic and environmental factors are essential in the etiology of schizophrenia [27]. Environmental factors can affect gene expression. In this Taiwan-based study, poverty is identified as a significant risk factor. This aligns with previous investigations as noted earlier. A comprehensive socioeconomic status measures economic and sociological issues of individual or household income, education, and occupation in relation to others. Interestingly, we focused on low-income as a modifiable factor for schizophrenia [28]. Understanding the etiology of the disease is relevant to affected persons. An integrated approach to poverty reduction would be essential in preventing the onset or progression of this disease among low-income groups.

Schizophrenia is one of the most disabling medical disorders in the world [29]. It has been reported that $45.8 \%$ ( $95 \% \mathrm{CI}=36.1 \%-55.5 \%)$ of patients with schizophrenia were individuals with low socioeconomic status [8]. However, in the analyses, the AR\% was not determined based on sex and age. In the present study, higher values of AR were observed in all individuals regardless of their gender and age group. This is similar to findings that have been previously reported [8]. 
In order to prevent schizophrenia, we may have to move from the epidemiological horizon to the public health foreground [28]. Lund et al. found that mental health effect of poverty alleviation interventions was inconclusive, although some conditional cash transfer and asset promotion programs had mental health benefits [30]. Additionally, Costello et al. reported that family income supplements in adolescence were effectively associated with a decreased risk of some mental disorders [31].

Our study has a number of strengths and limitations. First, it is the first population-based longitudinal study to confirm a relationship between low income and schizophrenia using a large sample size. Unlike most previous studies, we analyzed samples by sex and age group. As a limitation, we could not control some of the confounders such as other socioeconomic factors, comorbidity, and mental disorders. Second, diagnoses of schizophrenia in the NHIRD are based on clinical examinations by physicians, and hence may have been less reliable than those established through a structured diagnostic interview by trained researchers.

\section{Conclusion}

In this study, we found that low-income men had higher incidence rates of schizophrenia compared to women under 65. Overall, lowincome individuals had higher incidence rates compared to non-low-income individuals in all age groups and both sexes. Based on these findings, low-income is a risk factor for schizophrenia regardless of gender. Our study has substantial policy implications and the findings suggest the need for poverty alleviation interventions to support, especially low-income men aged 18-64 who appear to have a higher risk of developing schizophrenia.

\section{Conflict of Interest}

Authors declare that they have no competing interests.

\section{References}

1. Burns JK, Tomita A, Kapadia AS. Income inequality and schizophrenia: Increased schizophrenia incidence in countries with high levels of income inequality. Int. J. Soc. Psychiatry 60(2), 185-96 (2014).

2. Faris REL, Dunham HW. Mental disorders in urban areas: an ecological study of schizophrenia and other psychoses. 1939.

3. Castle D, Scott K, Wessely S, et al. Does social deprivation during gestation and early life predispose to later schizophrenia? Soc. Psychiatry Psychiatr. Epidemiol 28(1), 1-4 (1993).

4. Dauncey K, Giggs J, Baker K, et al. Schizophrenia in Nottingham: lifelong residential mobility of a cohort. Br. J. Psychiatry 163(5), 613-9 (1993).

5. Chan KY, Zhao Ff, Meng S, et al. Prevalence of schizophrenia in China between 1990 and 2010. Glob. J. Health. Sci 5(1) (2015).

6. Werbeloff N, Levine SZ, Rabinowitz J. Elaboration on the association between immigration and schizophrenia: a population-based national study disaggregating annual trends, country of origin and sex over 15 years. Soc. Psychiatry Psychiatr. Epidemiol 47(2), 303-11 (2012).

7. Bourque F, van der Ven E, Malla A. A meta-analysis of the risk for psychotic disorders among first-and second-genera- tion immigrants. Psychol. Med 41(5),897-910 (2011).

8. Agerbo E, Sullivan PF, Vilhjálmsson BJ, et al. Polygenic risk score, parental socioeconomic status, family history of psychiatric disorders, and the risk for schizophrenia: a Danish population-based study and meta-analysis. J. JAMA. Psychiatry 72(7), 635-41 (2015).

9. Sareen J, Afifi TO, McMillan KA, et al. Relationship between household income and mental disorders: findings from a population-based longitudinal study. Arch. Gen. Psychiatry 68(4), 419-27 (2011).

10. Byrne M, Agerbo E, Eaton WW, et al. Parental socio-economic status and risk of first admission with schizophrenia. Soc. Psychiatry Psychiatr. Epidemiol 39(2), 87-96 (2004).

11. Bhavsar V, Boydell J, Murray R, et al. Identifying aspects of neighbourhood deprivation associated with increased incidence of schizophrenia. Schizophr. Res 156(1), 115-21 (2014).

12. McGrath J, Saha S, Chant D, et al. Schizophrenia: a concise overview of incidence, prevalence, and mortality. Epidemiol. Rev 30(1), 67-76 (2008).

13. Chien IC, Chou YJ, Lin CH, et al. Prevalence and incidence of schizophrenia among national health insurance enrollees in Taiwan, 1996-2001. Psychiatry. Clin. Neurosci 58(6), 611-8 (2004).
14. Sutterland AL, Dieleman J, Storosum JG, et al. Annual incidence rate of schizophrenia and schizophrenia spectrum disorders in a longitudinal population-based cohort study. Soc. Psychiatry Psychiatr. Epidemiol 48(9), 1357-65 (2013).

15. Canuso CM, Pandina G. Gender and schizophrenia. Psychopharmacol. Bull 40(4), 178-90 (2007).

16. Caron J, Liu A. A descriptive study of the prevalence of psychological distress and mental disorders in the Canadian population: comparison between low-income and non-low-income populations. Chronic. Dis. Inj. Can.

17. Kessler RC, Heeringa S, Lakoma, et al. Individual and societal effects of mental disorders on earnings in the United States: results from the national comorbidity survey replication. Am. J. Psychiatry 165(6), 703-11 (2008).

18. Mojtabai R. Perceived reasons for loss of housing and continued homelessness among homeless persons with mental illness. Psych. Serv 56(2),172-8 (2005).

19. Lee CT, Chiang YC, Huang JY, et al. Incidence of Major Depressive Disorder: Variation by Age and Sex in Low-Income Individuals: A Population-Based 10-Year Follow-Up Study. Medicine 95(15), e3110 (2016).

20. Clarke MC, Harley M, Cannon M. The role of 
Relationship between Schizophrenia and Low-Income Based on Age and Sex: Results from a Nation-wide Population-Based Longitudinal Study

obstetric events in schizophrenia. 2005.

21. Anakwenze U, Zuberi D. Mental health and poverty in the inner city. Soc.Work. Health Care 38(3), 147-57 (2013).

22. Eaton W, Day R, Kramer M. The use of epidemiology for risk factor research in schizophrenia: an overview and methodologic critique. Handbook of schizophrenia 3:169-204 (1988).

23. Reijneveld SA, Schene AH. Higher prevalence of mental disorders in socioeconomically deprived urban areas in The Netherlands: community or personal disadvantage? J. Epidemiol. Community. Health 52(1), 2-7 (1998).

24. Goldberg EM, Morrison S. Schizophrenia and social class. Br. J. Psychiatry 109(463), 785-802
(1963).

25. Malama IM, Papaioannou DJ, Kaklamani $E P$, et al. Birth order sibship size and socioeconomic factors in risk of schizophrenia in Greece. Br. J. Psychiatry 152(4), 482-6 (1988).

26. Mulvany F, O'callaghan $\mathrm{E}$, Takei N, et al. Effect of social class at birth on risk and presentation of schizophrenia: case-control study. Bmj 323(7326), 1398-401 (2001).

27. Dean K, Murray RM. Environmental risk factors for psychosis. Dialogues. Clin. Neurosci 7(1), 69 (2005).

28. Kirkbride JB, Jones PB. The prevention of schizophrenia-what can we learn from eco-epidemiology? Schizophr. Bull 37(2), 262-
71 (2010).

29. Murray C, Lopez A. The Global Burden of DiseaseHarvard University Press. Cambridge, Massachusetts 1996.

30. Lund C, De Silva M, Plagerson S, et al. Poverty and mental disorders: breaking the cycle in low-income and middle-income countries. Lancet 378(9801), 1502-14 (2011).

31. Costello EJ, Erkanli A, Copeland W, et al. Association of family income supplements in adolescence with development of psychiatric and substance use disorders in adulthood among an American Indian population. JAMA 303(19), 1954-60 (2010). 